\title{
Review on Bovine Schistosomiasis and Its Associated Risk Factors
}

\author{
Banchiayehu Atanew Demlew, Asfaw Kelemu Tessma* \\ Bahir dar Zuria Woreda Administration, Bahir dar Zuria Woreda Veterinary Clinic
}

*Corresponding Author

Asfaw Kelemu

Article History

Received: 30.09 .2020

Accepted: 15.10 .2020

Published: 23.10 .2020

\begin{abstract}
Schistosome is a treamatode, snail-born parasitic of circulatory system in domestic animals and man. Ruminants are usually infected with cercariae by active penetration of the unbroken skin. It is an economically important disease caused by several Schistosoma species and results in economic losses through mortality and morbidity. The geographical distribution of Schistosoma species infecting cattle are mainly determined by the distribution of their respective intermediate host snails. The disease affects rural communities particularly those who depend upon irrigation to support their agriculture and drink contaminated water. Effective transmission of schistosomiasis occurs when the schistosome parasites, the aquatic snail hosts and the human or animal definitive hosts meet in space and time in surface water. The pathological changes with the disease are attributed by the adult parasite, cercaria and the eggs of the parasite. Health education, chemotherapy, environmental and biological control as well as provision of clean water have an innumerable role in the control activity of the disease. The use of traditional medicines in the treatment of schistosomiasis are economically important and a growing concern. There are various types of plants like Phytoplacca dodecandora (Endod) is the most widely used anti molluscicidal properties with minimal side effects used by developing countries and continuous to be used in the modern world. Diagnosis is based primarily on the clinico pathological pictures, parasitological techniques, post mortem findings, Serological techniques and Molecular diagnostic techniques .The most effective way to control cattle Schistosomiasis in endemic areas is to prevent contact between the animals and the parasite. Awareness creation about the disease, destruction of the snail intermediate host population at their breeding sites, either by chemical or biological methods may be considered as a recommendation to prevent the occurrence of bovine schistosomiasis.
\end{abstract}

Keywords: Bovine, Schistosomiasis, Epidemiology, Risk Factors.

\section{INTRODUCTION}

Ethiopia is localized in the tropical altitudes of Africa and has an extremely diverse topography and a wide range of climatic features and altitudes of agroecological zones, which makes the country suitable for different agricultural production systems. This in turn has contributed to the existence of large diversity of farm animal genetic resource in the country [1].

Livestock production constitutes one of the principal means of achieving improved living standards in many regions of the developing world. In subSaharan Africa countries livestock plays a crucial role both for the national economy and the livelihood of rural communities. It provides draught power and raw material for industry [2]. In Ethiopia, livestock contribute about $30-35 \%$ of agricultural gross domestic product (GDP) and 12-16\% of total GDP [3].
Ethiopia has one of the largest livestock populations in Africa. According to CSA [4], the country has 57.83 million cattle, 29.33 million sheep, 29.11 million goats, 1.23 million camels, 60.51 million poultry, 2.08 million horses, 0.41 million mules and 7.88 million donkeys. Livestock play an important role in providing export commodities in the form of live animals and hides and skins [5].

The country has the laregest cattle population which helps to improve the livelihoods of the community especially pastoral communities in the country [6]. It serves as productive, financial, social asset, means of investment, important source of cash income and ensuring food security [7]. However, the cattle production and productivity is below the expected potential due to widespread of animal diseases, inadequate and poor quality of animal feed; limited veterinary services; poor selection and breeding and

Copyright $\odot 2020$ The Author(s): This is an open-access article distributed under the terms of the Creative Commons Attribution 4.0 International License (CC BY-NC 4.0) which permits unrestricted use, distribution, and reproduction in any medium for noncommercial use provided the original author and source are credited. 
lack of proper technology package. Among the bottle neck challenges of cattle production, trematode parasites are the main once [8].

Flukes of ruminants are flat worm (trematodes) parasites living in liver (Fasciola) proventriculus (Paraphistomum) or blood (Schistosoma). The occurrence of the parasites is depending on the suitable ecological conditions for the growth and multiplication of intermediate host (snails) [9].

Schistosomes are dioecious parasitic flatworms, which live in the vasculature of their mammalian definitive hosts. They are the causative agent of schistosomiasis, a disease of considerable medical and veterinary importance [10]. Schistosomiasis is snail-borne trematode infection of man, domestic animals and wild animals in different parts of tropical and subtropical countries [9].

The geographical distribution of bovine schistosomiasis has been determined primarily by the distribution of snail intermediate host particularly Bulinus species which are important for the occurrence of disease in bovine species. Schistosoma bovis is a species' whose final hosts are bovines, ovines, caprines and whose secondary hosts are small wild ruminants. They are distributed throughout Africa, South West Asia and Mediterranean, Europe [11].

These parasites cause a significant economic loss which includes death, loss in carcass weight, reduction in milk yield, decline production and productive performances, exposure of animals to other diseases due to secondary complications and cost of treatment expenses [12]. Moreover; the public heath significance of Schistosomosis has been reported from different parts of the world including Ethiopia. Human acquire infection through ingestion of metacercariae that are attached to certain aquatic plant and vegetables [13].

The major transmitting sites of the disease are small streams all over the highlands of Ethiopia, lakes like Tana, as well as irrigation systems, such as sugar state [14]. The transmission of schistosomiasis takes place only in the place where fresh water snail vector is present and where there is contact between the host and infested water [15].
Animal and human schistosomiasis is dependent on environmental factors such as moisture, rainfall, temperature, water bodies (stagnant ponds, swamps, streams, rivers, irrigation canals, marshes and dams) and snail intermediate hosts [16].

Moreover, schistosome infection is closely associated with infested water bodies with traditional grazing and watering systems [17]. These factors tend to be conducive of enzootic schistosomiasis, which is characterized by the high prevalence and significant losses of productivity in ruminant population [18].

Age, sex, breed, season, immunity, anthropogenic/ human, farming system and environmental factors are also playing the role for the prevalence and occurrence of schistosomiasis infection rate in animals. The young parasites cause some damage during migration, but the principal lesions and pathology are associated with passage of the spined eggs through the tissue of the gut lumen of intestine and other organs, and blood sucking habit of the helminthes worm [19].

Praziquantel is highly effective for the treatment of bovine schistosomiasis. Treatment of schistosomiasis helps in reversing acute or early chronic disease, preventing complications associated with chronic infection and preventing neuroschistosomiasis. The most effective way to control cattle schistosomiasis in endemic areas is to prevent contact between the animals and the parasite [20].Therefore the objectives of this review were to explain the etiology, epedimology, diagnosis, treatment of Bovine Schistosomiasis, and to describe the risk factors ,transmission, and economic importance of Bovine Schistosomiasis.

\section{Etiology}

Schistosomes are thin, elongated flukes up to $2 \mathrm{~cm}$ long primarily parasitizing blood vessels of the alimentary and bladder responsible to cause schistosomosis[21]. 
Schistosomiasis or Bilharziasis is a disease caused by trematodes of the genus Schistos ma with different species. The taxonomic classification of the organism is presented as kingdom Animalia, Phylum Platyhelminthes, class Trematoda, sub class digenea, Family Schistosomatidae, Genus Schistosoma and a total of nineteen [22]. Different species are described worldwide and they can be differentiated between from their morphological features, lifecycle, host specificity, enzyme and DNA and behavioral [23]. Veterinary important species of Schistosoma that cause major impact on domestic animals include Schistosoma bovis (ruminants in Africa and Asia), Schistosoma leiperi (cattle inAfrica), Schistosoma spindale (ruminants, horse and pigs in Asia), Schistosoma nasale (ruminants and horse in India), Schistosoma indicium (horse, cattle and goats in India buffalo), Schistosomaja ponicum (human, and mammals in Asia) and Schistosoma margrebowiei (horses, ruminants and elephants in Africa) [24].

\section{Morphology}

The Schistosome parasites are elongate, unisexual and dimorphic trematodes, which inhabit the blood vessels of their hosts. The female is slender and usually longer than the male and the female is carried in the gutter -like groove, the gynaecophoric canal of the male [19]. The average length of adult male was $(16.7 \pm 1.3 \mathrm{~mm})$ and it had two suckers (oral and ventral) and distinct gynaecophoric canal and 3-6 testicles situated behind the ventral sucker, and in all specimens showed male holding the threadlike female in gynaecophoric canal. In fact it seems that females cannot mature in absence of the males (Figure 1). As in other flukes the digestive system of Schistosoma is blind, i.e. it has no anus but ends in a blind branch, the cecum. Schistosoma eggs have species-specific sizes (130-300x40-90 micrometers) and are oval to spindleshaped, with or without spines [25]. The Schistosomes are different from most other members of the digenea, the sexes are separate. The term Schistosome or Schistosoma means split body and refers to the fact that the males have a ventral groove called gynaecophoric canal [26].

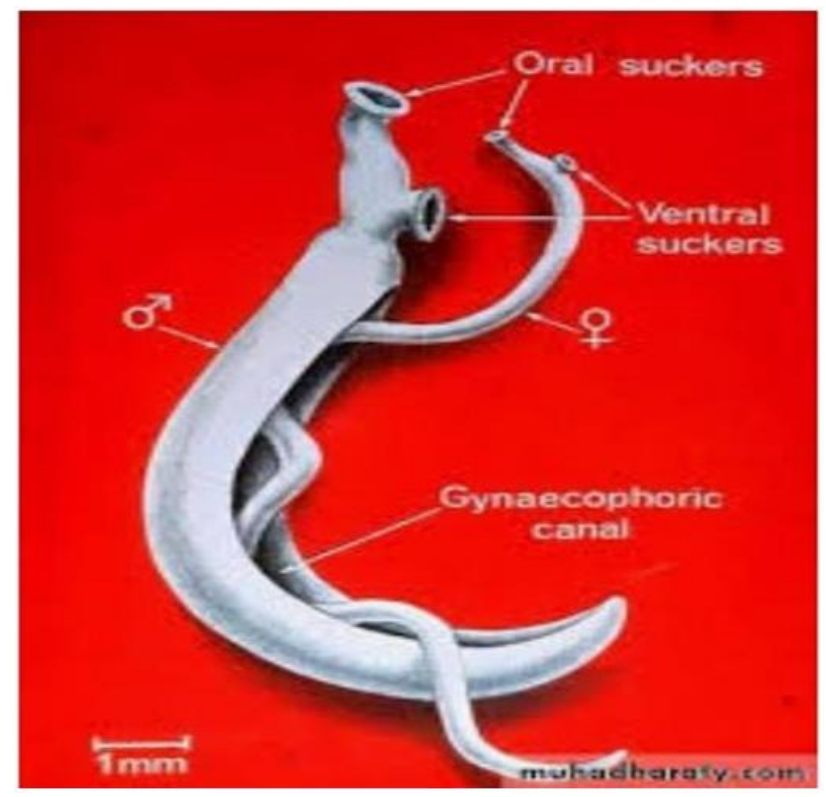

Fig-1: Morphological characteristics of adult Schistosoma [27].

\section{Epidemiology}

Schistosomiasis is closely associated with large permanent water bodies such as ponds, lakes and marshy pastures. The distribution of the disease has been primarily determined by the distribution of snail intermediate host, particularly Bulinus and Physopsis species which are important for bovine Schistosomiasis [21].

Schistosoma species of animals are widely distributed in the tropical and sub-tropical region of the world. These include Schistosoma bovis commonly found in cattle, goat and sheep in Africa and Southern Europe, Schistosoma mattheeii normally parasite of sheep, cattle and other domestic animals in southern parts of Africa, Schistosoma magrebowiei in Antelopes in Central Africa and Schistosoma rodhaini normally parasitic in wild rodents and in carnivores in Eastern and Central part of Africa. Other species of veterinary importance in Asia include Schistosoma spindale, Schistosoma indicum, Schistosoma incognitum, Schistosoma nasale and Schistosoma leiperi [28]. 
Schistosoma bovis has a localized distribution in Ethiopia and has been recorded in slaughter houses in various region of the country. The prevalence of Schistosoma bovis has reported from different regions of the country by fecal examination. For example, in Bahir Dar it was 33.8\% reported by Solomon [29], 28\% in Kemissie by Ameni et al., [30] in cattle and $15.5 \%$ in Bahir Dar by Haile [31], in small ruminants were evident.

\section{Intermediate Host}

All Schistosomes need snails as their intermediate hosts to complete the asexual phase of their life cycles [32]. The snail intermediate hosts for bovine Schistosomes belong to the genus Bulinus, Indoplanorbis and Planorbis. An important genus in Africa is Bulinus. Bulindis are grouped into africanus group, truncatus/tropicuscomplex, forsicalli group and reticulates group [33]. Intermediate hosts of Schistosoma mattheei belong to the Bulinus africanus group while those of Schistosoma bovis belong to truncatus/tropicus complex as well as to the africanus group and farcically groups. In Ethiopia Bulinus truncatus, Bulinus africanus and Bulinus abysinicus serve as the intermediate hosts of Schistosoma bovis. Schistosoma mattheei has not been recorded in Ethiopia so far [28]. Bulinus africanus and Bulinus truncates were identified harboring schistosoma cercariae confirmed by the experimental infection of mice with these cercariae. Other snails identified were. Biomphalari apfeifferi and Lymnea natalensis. Bulinus species were identified at all sites [34].

\section{Risk factors for infection Host related risk factors Age}

Due to a long exposure time because older animals move long distances in search of scarce pastures and water thereby increasing their chances of infection as well as becoming infected at overcrowded watering holes, infection rate increased with the increase of age and peak infection occurred at the maturity of age [35]. On the other hand, the very young calf do not graze extensively as the older do, so they get less infection of cercariae unlike adult animals [24].

\section{Sex}

Differences in susceptibility to infection between sexes have been observed by various workers. The observed disparity results in differences in exposure [36]. The reason seems to be related to social practice of keeping females under better management and feeding condition for milk production and breeding whether males are generally let lose to graze freely in pasture and infrequently used for draught purpose and also more stressed. Males are also fed relatively poor diet which increases the susceptibility to parasitic infection [37].

\section{Breed}

Local breeds are more affected by schistosomiasis than cross breeds. This difference in prevalence of the disease does not due to the difference in susceptibility but due to the difference in exposure. Cross breeds are mostly kept for dairy or fattening purpose and they are mostly housed and supplementing good feed and clean water which reduce their access to the cercariae. However, the local once are mostly managed extensively to graze freely and get access to infective stage of the parasite [38].

\section{Immunity}

In older animals, faecal egg counts remain low, tissue egg counts seem to follow the pattern of the faecal egg counts, while worm burden tends to increase with the age of the host [39].

This suggests the development of an acquired immunity, which mainly acts through a reduction of the fecundity of the female worm, expressed as reduced faecal, and tissue egg counts, with few effects on worm burden. However, evidence is accumulating that with increasing duration of exposure to continuous challenge, cattle also become less susceptible to reinfection. Examination of naturally infected animals has shown that partial protection against reinfection also occurs, and acquired resistance to schistosomes is of major importance in the regulation of infection intensity in the field [25].

Reductions in worm burden and egg counts could also be induced in non-immune calves, which received serum from immune donors [40].

A few studies reported on heterologous resistance. Calves previously exposed to infection with the human schistosomes like Schistosoma mansoni and Schistosoma haematobium were partially protected against Schistosoma mattheei and Schistosoma bovis, and it was believed that this type of heterologous resistance might be of considerable importance in protecting cattle from the more serious effects of schistosomiasis [41].

\section{Seasonal risk factors}

Schistosome infection rate in cattle increases $\mathrm{d}$ uring rainy season, because of the abundance of snails and their rapid multiplication and dispersion. Furthermore, dispersion of fecal matter occurs due to rain splashes. These factors may enhance the infection of snails by miracidia and cercarial contamination to adjacent areas through water. During this time conditions on the lands are suitable for the survival of the intermediate hosts and they become heavily infected with the schistosome larval stages. So, cattle are prone to get the infection of schistosomes [19]. But in dry season infection rate of the schistosome parasite is low because of harsh dry conditions and less chances of 
infection due to unavailability of snail intermediate hosts as the water sources are scarce in this season [25].

\section{Management risk factors}

Cattle schistosomiasis is dependent on environmental factors such as moisture, rain fall, temperature, presence of water bodies (stagnant, swampy, and marshy) and snail intermediate hosts. Husbandry practice such as grazing system, keeping animals whether they are kept all together and /or separately, feeding and drinking areas [42].

Due to the better management practices and sanitation, infection rate reported to be low in intensive farming system where animals are mainly stall fed. proper management practices and policy change towards urban husbandry can minimize the Schistosomiasis prevalence. They also reported that when cattle are slaughtered through back yard system and consequently the stomach and other intestinal contents including blood and washed materials are dumped into the nearby water bodies' prevalence of the disease also increases [43].

In the extensive and semi-intensive system of rearing where animals grazing in the fields have more risks of getting contact with water and subsequently with the infective stage, cercaria. Moreover, increasing cattle mobility through trading and or rental potentially increases the possibility of spreading the disease or infection sources [25].

\section{Human /Anthropogenic factors}

Transmission rates of schistosomiasis increases due to Construction of water schemes to meet the power and agricultural requirements for development [44].

Water development projects are the major factor associated with the increase of schistosomiasis, particularly manmade lakes (hydroelectric power) and irrigation schemes (agriculture), which can lead to shifts in snail vector populations. Many surface irrigation systems in Africa create favorable snail breeding conditions that facilitate the transmission of schistosomiasis [45].

Factors like the variability within irrigated areas, the canal type, the distance of sites from the canal, the composition and density of aquatic vegetation), the season [46], specific local conditions such as water stagnation, water depth and shading [47] and water flow velocities and the location of breeding sites are affect the presence and density of snails among sites. Low-flow velocities and locations found at the starting point of low-order canals are favorable to get aeration of the water and food availability for snails [48].

\section{Transmission}

The infective stage of Schistosoma is fully mature, cercariae which are leave in the snail and swim freely in the water, where they remain viable for several hours. Ruminants are usually infected with cercariae by penetration of the skin, although infection may be acquired orally while animals are drinking. During penetration, cercariae develop into schistosomula, which are transported via the lymph and blood to their predilection sites of mesenteric and hepatic veins of the host (except for Schistosoma nasale, which lives in the nasal veins), [25]. where they feed on blood and produce eggs with a characteristic terminal or lateral spine. Eggs passed in the feces must be deposited in water, hatch and release miracidia, which invade suitable water snails and develop through primary and secondary sporocysts to become cercariae [49]. The prepatent period varies according to the species but is generally 45-70 days. The increased host range of the hybrid parasites and changes in host distribution seen in Africa may have a direct impact on transmission of these schistosomes. Laboratory hybrids have been observed to acquire enhanced characteristics such as infectivity, fecundity, and growth rates [25].

\section{Life Cycle}

Schistosomes are dioecious (unisexual) worms, which are an exception among the trematodes and have an indirect life cycle, while water snail act as an intermediate host belong to the genera Bullinus and planorbis are required to complete their life cycle [50].

After copulation of male and female schistosomes within the lumen of vein, adult female moves against the venous blood flow in to small venules, when she deposited 200-2000 eggs per day. The ova pass through the wall of blood vessels, and then to adjacent tissues. The ova may be discharged in feces or urine and large amount may be trapped in tissues of the final host .In the water, eggs are hatched and release miracidia. The miracidia then invade suitable water snails and develop in to cercariae. When cercariae are fully matured, they leave the snail and invade the final host through the skin or mucus membranes after penetration; cercaria develops into schistosomula, which are transporte through the lymph and blood to their predilection sit s [51]. 


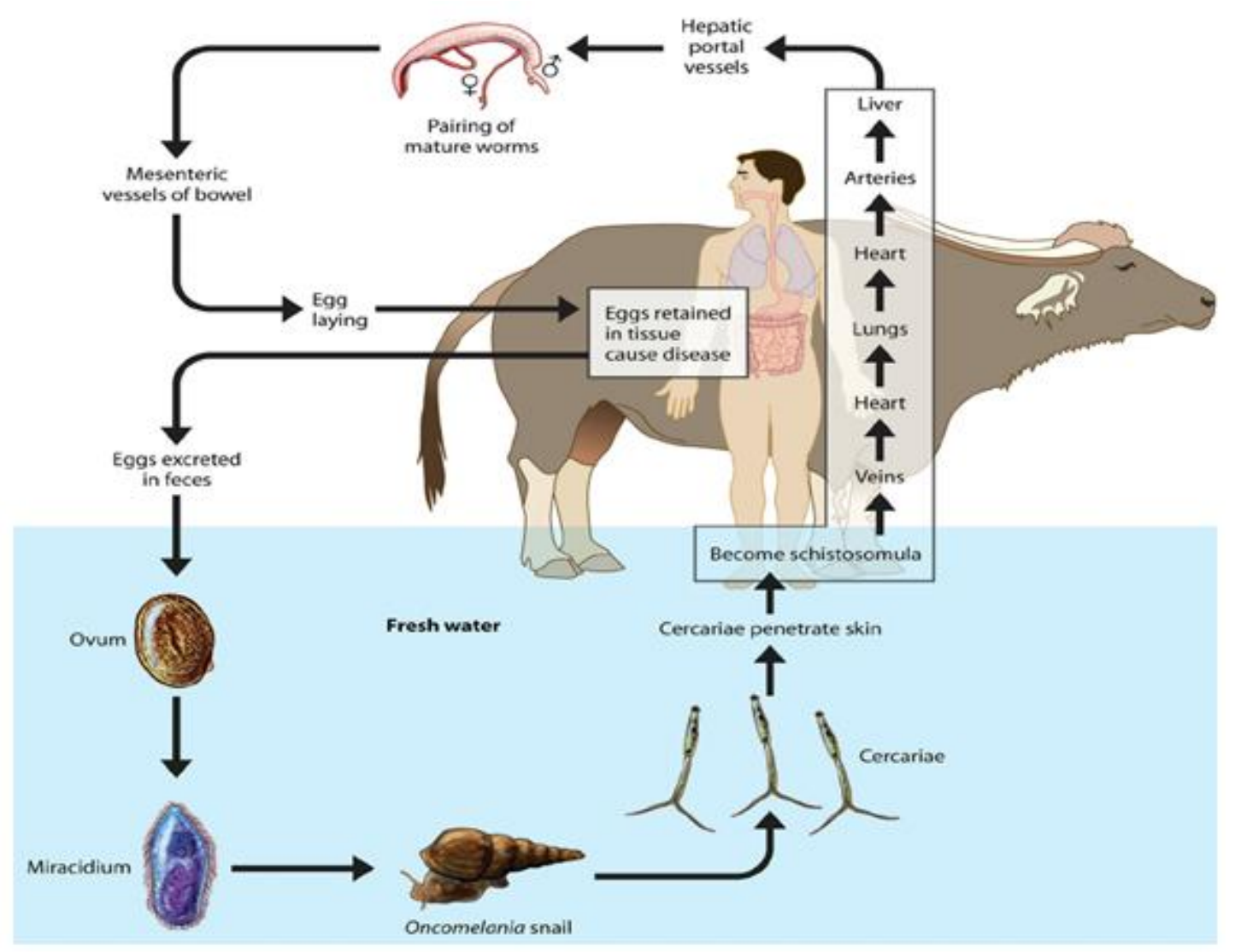

Fig-2: Life cycle of Schistosoma [52]

\section{Pathogenesis and pathology}

The fully matured cercariae are leaving the snail and invade the final host through the skin or mucous membranes. After penetration cercariae develop in schistosomula, which are transported through the lymph and blood to their predilection sites [51]. The migration of the eggs may cause mechanical damage and lesions. Moreover, Schistosoma eggs trapped in the tissue elicit granulomatous reaction that is mounted to destruct the eggs. These granulomas consist of several cell types, mainly eosinophils, macrophages and lymphocytes [53]. In the chronic stages of the disease, the pathology is associated with collagen deposition and fibrosis, resulting in organ damage and dysfunction [54].

The adult parasites are known to be haematophagus and the worm in the viscera can also causes tissue reaction when it is dead. The adult worms lay eggs in the mesenteric vein and as much as $40-80 \%$ eggs laid is retained inside the body and it is the retained eggs and their products that are responsible for most morbidity [55].

Pathologies of infections are highly associated with the eggs and the intensity of the pathogenic effects depends on the duration of the infection and the number of Schistosomes present. Adult parasites in the vascular system can cause lesions. Cercaria induced skin lesions have been also described [51].

\section{CLINICAL FINDINGS}

The principal clinical signs are associated with passage of the spined eggs through the tissue of the gut lumen. The young parasites cause some damage during migration, but most of the lesions are due to the irritation produced by the eggs of parasites in the intestine and other organs, and blood sucking habit of the helminthes worm. The helminthes worm may also enter the vesical veins and they may cause hematuria [19].

Diseased animals shown unthriftness, anorexia, intermittent diarrhea mixed with blood or mucous, dehydration, sunken eyes, pallor of mucus membrane, more over severe emaciation and thirst were also encountered. Systemic reactions were mild however; pale mucous membrane, polypnea and nasal discharge were also seen [56].

Signs associated with chronic hepatic disease may develop when eggs are washed back to the liver by the portal circulation during their penetration of the gut wall. The eggs become lodged in the liver and an intense immunological response results, followed by the formation of a granuloma. A large proportion of the liver may be destroyed and the liver function severely disturbed [42]. 


\section{Diagnosis}

Diagnosis is based primarily on the clinicopathological picture, seasonal occurrence, previous history of schistosomiasis in the area or the identification of snail habitats with a history of access to natural water bodies, demonstration of characteristic eggs based on the species in the feces, postmortem examination and hematological tests [57].

\section{Clinical signs}

Weight loss, poor weight gain, diarrhoea, loss of appetite, roughness of the skin, and pale mucous membranes of Cattle are a syndrome developed by Schistosoma bovis. These signs are usually observed by 6-7weeks after exposure to the infective stage,the cercariae. The severity of these signs increases between the $7^{\text {th }}$ and the $9^{\text {th }}$ week, where the fecal egg counts are highest. However, the clinical signs of the disease are unreliable as other trematodes parasites may produce similar clinical signs [25].

\section{Postmortem findings}

Thousands of visible Schistosoma bovis adult worms are found in the mesenteric veins during diagnosis at necropsy. Infected livers are diagnosed on the basis of the presence of macroscopic lesions of schistosomiasis visible as white-gray foci under the liver capsule and within the substance of the liver [58].

\section{Parasitological techniques}

Detecting eggs of the parasite in feces or biopsy specimen of the infected animal is the only definitive diagnosis of an active Schistosoma bovis infection. The eggs of animal Schistosoma parasites differ in size and shape; oval in Schistosoma japonicum and spindle shape in Schistosoma bovis and Schistosoma mattheei containing single spine protruding from the shell. The position of the spine on the egg shell is a distinguishing feature; a rudimentary lateral spine in ova of Schistosoma japonicum and terminal spines in others [51]. Sedimentation technique the most commonly used method for detection of fecal egg excretion under field condition. In general when schistosomiasis is suspected, diagnosis is best confirmed by a detailed postmortem examination which reveal lesion and if mesentery is stretched, the presence of numerous Schistosomes in the veins [59].

\section{Serological techniques}

An active Schistosoma bovis infection does not necessarily identified by Serology. However, this method is useful to determine past infection in a seroepidemiological survey. The serological techniques applied for diagnosis of Schistosoma bovis include intradermal test for immediate and delayed hypersensitivity; serological tests based on agglutination reaction, e.g. indirect hemagglutination test; the precipitation tests such as circumoval precipitin test, Cerkarien Hulien reaction, agar gel immunodiffusion, the complement fixation test and the indirect labeled antibody technique such as the indirect immunofluorescence antibody technique, the enzyme linked immunosorbent assay and immunoblotting such as westem blots [60].

\section{Immediate and delayed hypersensitivity test}

The test has not been described for the diagnosis of bovine schistosomiasis on a practical scale. Adult worm antigen has proven satisfactory for detection of immediate and delayed skin test. However, cercarial antigen was found to be of little value because of the large number of the false positive reaction. A positive result is indicated by increased thickness of the skin at the site of the injection [60].

\section{Circumoval precipitin test (COPT)}

This test requires preparation of viable eggs. A positive result is indicated by the presence of globular or long chain type of precipitate around the eggs. The test was reported to be sensitive and specific by several workers [61].

\section{Cerkarian Hulien reaction}

In this test a positive reaction is indicated by formation of an envelope or a precercarial sheath around the cercariae. It is simple and sensitive. However, it requires live infectious cercariae which limit its use under field condition as cercariae are only available in a laboratory maintaining infected snails [60].

\section{Agar-gel immunodiffusion test (AGID)}

The method adopted was basically that described by Ouchterloney [62] with the modification of Aradaib et al. [63] Precipitin lines were seen when S. bovis adult worm antigen was tested against hyperimmune será from Schistosomabovis infected rabbit and mice $[64,65]$. Precipitin lines were also observed with sera from calves experimentally infected or immunized with Schistosomabovis adult worm extracts or whole-egg antigen [66]. Cross reactions in the AGID between whole-egg, cercarial or adult worm antigens

were also observed [67]. No precipitin lines were obser ved with sera from calves experimentally immunized with irradiated Schistosoma bovis schistosomula [66].

\section{Indirect fluorescence antibody technique (IFAT)}

The test was first described by Hussien [68]. A positive result is indicated by presence of specific fluorescence. The IFAT was found to be $95 \%$ sensitive for the diagnosis of Schistosoma mansoni using adult worm antigen. The specificity decreased very sharply when cercarial antigen was used due to large number of false positive reaction [69]. Hussien [68] applied the test for serodiagnosis of Schistosoma bovis infection in calves and suggested that partially purified Schistosoma bovis adult worm may be used as antigen for diagnosis of bovine schistosomiasis. 


\section{Complemeni fixalion test (CFT)}

The CFT requires the use of sensitized RBCs of sheep. A positive result is indicated by absence of RBCS hemolysis due to fixation of the complement by the antigen-antibody reaction, whereas hemolysis indicates a negative test. A large number of false positive reactions were obtained when using cercarial antigen [68]. The test has a great value for diagnosis of bovine schistosomiasis using adult worm antigen. However, the test is complicated, highly delicate technique and is not suitable for field operation [64].

\section{Enzyme linked immunosorbent assay (ELISA)}

The microplate modification version of ELISA was first described by Voller et al., [70] The potential of ELISA for diagnosis of a variety of parasitic infections has been investigated, more sensitive than earlier serological tests and more used in developing countries since minimal laboratory equipments are required. In addition, ELISA can be used as a superior diagnostic altemative to other serological test because it is a simple, rapid, inexpensive and sensitive test. One of the major problems in the apphcation of ELISA for diagnosis of bovine schistosomiasis is the av ailability of suitable and specific antigens that can be used to avoid or to minimize false positive results due to cross reactions with other helminth infections. Huldt et al., [71] were the first authors to detect antibodies to human schistosomes by ELISA and Aradaib [72] was the first author to detect antibodies to bovine schistosomiasis. Both authors noted the potential of ELISA for seroepidemiological study of schistosomiasis. Most investigators have used crude or partially purified antigens $[65,72,73,66]$. Application of soluble egg antigens (SEA) had commonly been reported to yield a better results than adult worm antigens (AWA), irrespective of their purity .Cross reactions between Schistosoma bovis AWA and SEA in the ELISA with characteristically lower absorbance values to heterologous antigen was observed [72]. A variety of different antigenic preparations for the diagnosis of human schistosomiasis were described. However, little work has been carried out in relation to the species of veterinary importance. A purified Schistosoma japonicum SEA increased the specificity and the sensitivity of the ELISA to $100 \%$ to $98 \%$ [74].

\section{Immunoblotting technique}

The technique is highly sensitive and specific that has been recently introduced for detection of Schistosoma bovis defined or recombinant antigens against specific IgG antibodies. Westem blots are first incubated with antiscra at room temperature and then with labeled antibody at room temperature and finally a substrato is added for visualization of the antigenantibody reaction at the expected weight of the protein using molecular weight marker. Using westem blots, será from calves vaccinated with defined or recombinant Schistosom abovis or Schistosoma mansoni $28 \mathrm{KD}$ proteins recognized protein bands at a molecular weight of $28 \mathrm{KD}$ by 3 weeks post vaccination. The technique is useful to study the immune response of animals to schistosome vaccines as well as correlation between antibody production and protection $[72,75]$.

The serological techniques mentioned previously, despite their advantage in detecting Schistosoma bovis infected individuals, are complicated by cross reactions between other trematode parasites and within different species of schistosomes. To address these problems, molecular diagnostic techniques have been developed [60].

\section{Molecular diagnostic techniques}

The gene coding for schistosome glutathioneS-transferase (GST) has been identified, cloned and sequenced [76]. Nucleic acid hybridization techniques using Complementary DNA probes have been developed for detection of nucleic acid sequence of schistosome GSTs. Primers-directed reverse transcriptase (RT) polymerase chain reaction (PCR) for sequencing of schistosome GSTs was also described [77]. All these molecular studies have been carried out in an attempt to produce an effective broad spectrum antischistosome vaccine. However, no work has yet been conducted in molecular diagnosis of schistosomiasis on a practical scale. These molecular diagnostic techniques probably will provide the basis for future diagnostic tests [60].

\section{Socio-economic and public health significance of the disease}

In addition to the high prevalence, outbreak of the disease and increased susceptibility to other parasitic and bacterial disease, the disease has an economic impact like production losses due to Schistosoma bovis that results from mortality, delayed growth, partial liver condemnation and poor future reproduction performance and sub clinical infections cause significant losses due to long term effects on animal growth and productive capacity or milk yield and draft power [78].

Schistosomiasis is one of the most prevalent parasitic diseases and an important public health problem in many developing countries. Globally, schistosomiasis ranks second among parasitic diseases of socio economic and public health importance and is found in 48 African countries [79]. An estimated 779 million people are at risk of schistosomiasis, of whom 106 million (13.6\%) live in irrigation schemes or in close proximity to large dam reservoirs and the majority of these infections occur in Sub-Saharan africa [80].

It is prevalent in tropical and subtropical areas especially in poor communities that had low access to safe drinking water and adequate sanitation. It is estimated that at least $90 \%$ of those requiring treatment for schistosomiasis live in Africa [81]. It was listed 
among the 13 diseases classified by World health organization as "Neglected Tropical diseases [82].

\section{Treatment}

Although schistosomiasis not eradicable, the disease can be prevented and transmission controlled with a single annual dose of praziquantel [83]. Main control options are the supply of pure drinking water, diagnosis and treatment of positive cases, management of the environment and control of the intermediate hosts or fresh water snails [82].

Praziquantel is highly effective for the treatment of bovine schistosomiasis. Treatment of schistosomiasis helps in reversing acute or early chronic disease, preventing complications associated with chronic infection and preventing neuroschistosomiasis. The goal of treatment is reduction of egg production via reduction of worm load: this reduces mortality and morbidity [20]. Care has to be exercised in treating clinical cases of schistosomiasis since the dislodgement of the damaged flukes may result in emboli being formed and subsequent occlusion of major mesenteric and portal blood vessels with fatal consequences [21].

\section{Control and prevention}

The most effective way to control cattle schistosomiasis in endemic areas is to prevent contact between the animals and the parasite. Unfortunately, this is not always possible in parts of the world where nomadic conditions of management prevail. Other methods of control include destruction of the snail intermediate host population at transmission sites, either by biological methods or chemical, or their removal by mechanical barriers or snail traps and ecological measures [33].

Biological control of blood flukes (i.e. using their natural enemies) is so far not feasible. However there are medicinal plants which are affective against external and internal parasites. Ecological measures against the snails that aim to render their habitat unsuitable for survival, such as drainage, removal of water weeds, and increased water flow, are important controling methods of parasitic trematodes and have water snails as intermediate hosts and frequently are found in the same localities as schistosomes [25].

From the current available chemical Bayluscide (Niclosamide) and copper sulfate are the choices for molluscicide. In addition to these, a native Ethiopia plant, phytoplaca dodecandora, locally known as "endod" is also an effective molluscicide [14].

In human, the most effective way of controlling Schistosomiasis are the provision of sanitary facilities and piped water since; it reduces human contact with contaminated water [13].

\section{CONCLUSION RECOMMENDATION}

AND

Schistosomiasis is a chronic debilitating infection of humans and animals caused by different species of schistosomes. Cattle schistosomiasis caused by Schistosoma bovis is one of the major veterinary problems. Occurrence of bovine schistosomiasiis dependent on environmental factors such as moisture, rain fall, temperature, water bodies (stagnant, swampy and marshy) and snail intermediate hosts. Although there has been little recognition of its veterinary significance, cattle schistosomiasis can cause significant loss throughout the world. This is due to the nature of the disease which occurs at subclinical level with long term effect on the animal growth and productivity and increased susceptible to other parasitic and bacterial disease. High prevalence of chronic schistosome infections causes significant losses on a herd basis. Although the economic significance of the disease is mainly attributed to morbidity, mortality, liver condemnation, reduced productivity and poor subsequent reproductive performance.

- Therefore, further study on the epidemiology of the disease like malacological and parasitological survey, and mapping high risk areas,

- destruction of the snail intermediate host population at their breeding sites, either by chemical or biological methods should be carried out for sound prevention and control of schistosomiasis.

- Habitat modification and drainage or increasing of water flow activities should be practiced

- Human being after swimming must be washed their bodies with soap and dry with clean towel

- Well-planned deworming activities are essential in order to reduce the exposure rate of animals to Schistosoma and the impact of schistosome infection in the area.

\section{ACKNOWLEDGEMENTS}

First I glorify living GOD with saint virgin marry, the supper master of the world, without his mercy I am not being a person today. Next I would like to thank my friends for their moral and material support.

\section{REFERENCES}

1. Anon, J. (2004). States of Ethiopians animal genetics resources country report. A contribution to the first report on the state of world's animal genetic resources. Institute of biodiversity conservation (IBC), Addis Ababa Ethiopia, 1-54.

2. ILCA. (2007). Annual Report. Addis Ababa, Ethiopia, 34-38.

3. Animal, animal products and byproducts Market D evelopment Authority (AAPMDA). (1999). Market Problems and Measures to Be Taken. 
4. CSA, (Central Statistics Authority). (2015). Federal Democratic Republic of Ethiopia, Agricultural sample survey on livestock and livestock production (Private peasant holdings), Statistical Bulletin No. 532, Addis Ababa, Ethiopia, 2, 9-20

5. FAO. (Food and Agricultural Organizations of the United States). (2009). Livestock sector brief, Ethiopia livestock information, and sector analysis and policy branch. FAO, Rome, Italy, 15-16.

6. Central Statistical Agency (CSA), (2014/15). Federal Democratic Republic of Ethiopia central statistical agency, agriculture in figure key findings of the 2014/15 agricultural sample surveys or all sectors and seaso ns country summary, FDRECSA, Addis Ababa, Ethiopia.

7. Ministry of Information (MOI). (2015). Export products of Ethiopia. Press release of Ministry of Information, Department of press and audiovisual. Addis Ababa, Ethiopia.

8. Yeneneh, A., Kebede, H., Fentahun, T., Chanie, M. (2012). Prevalence of cattle flukes infection at Andassa Livestock Research Center in northwest of Ethiopia. Veterinary Research Forum, 3(2):8589.

9. Urguhart, G., Armour, J.,Duncan, A., Dunn, W., \& Jennings, F. (2003). Veterinary Parasitology2nd edn. Black well science. Scotland, 277:117 -120.

10. Rollinson, D., \& Southgate, V.R. (1993). The Genus Schistosoma. A taxonomic appraisal. In D. Rollinson and A.J.G Simpson (EDs), the biology of Schistosomes form genus to latrines London: Academic press, pp: 1-49.

11. Singh, A., \& Chaudhri, S. (2004).Visceral Schistosomiasis of domestic animals in India: humoralimmune status of infected cattle, s heep and goat against

mainy poly peptide antigens of Schistosoma indicu $\mathrm{m}$ and Schistosom spidle.parsite and immunology, 26:167-175.

12. Mogdy, H., Al-Gaabary, A., Salaam, A., Oman, M., \& Amperage, G. (2009). Studies on Paramphistomiasis in ruminants in Kafrelsheikh. Journal of Veterinary Medicine, 10: 116-136.

13. Mohammad, A., \& Waqtola, C. (2006). Medical Parasitology in Jimma University, Jimma Ethiopia, USAID, 284-300.

14. Shibru, T., Getachew, T., Hailu, B. (1989). Parasitology. Schistosomiasis in Ethiopia. Addis Ababa.Addis Ababa printing press, 18-26

15. Okpala, HO. (2004). A survey on the prevalence of schistosomiasis among pupils in Apata and Larant o areas in Jos, Plateau State, 3(1). Federal College of Veterinary and Medical Laboratory Technology, National Veterinary Research Institute, Vom, Plateau State,Nigeria.

16. Li, S., Qian, Y, Yang, K. (2012). Successful outcome of an integrated strategy for the reduction of schistosomiasis transmission in an endemically complex area. Geosp Hlth, 6(2): 215220.

17. Arshad, G., Maqbool, A., Qamar, M. (2011). Epidemiology of schistosomiasis in buffaloes under different managemental condition in four districts of Punjab, Pakistan. J Anim Plnt Sci, 21(4): 841843.

18. Islam, K.S. (2011). Schistosomiasis in domestic ruminants in Bangladesh. Tropical Animal Health and Production, 7(4): 244-248.

19. Soulsby, E. (1982). Helminthes, arthropods and protozoa of Domesticated animals. London: Bailliere Tindal; pp. 136-160.

20. Richer. (2003). The impact of chemotherapy on morbidity due to schistosomiasis. Acta trop: $86(2-$ 3): 161 .

21. Urquhart, G.M., J.Armor, J.L.Duncan and F.W. Jen ning.(1996). Veterinary helmintho logy Veterinary Parasitology. NewYork Churchill Livingstone Inc., 114-116.

22. Aiello, S.E., \& A. Mays. (1998). The Merck veterinary manual. 8th ed. Merck and $\mathrm{CO}$, Inc,White house Station, N.J, U.S.A., 29-31.

23. Rollinson, D., \& U.R. Southgate. (1987). The Genus Schistosoma. A taxonomic appraisal. In: D. Rallinson and A.J.G- Simpson (eds), the biology of Schstosomes from genus to latrines, London Academic press, 1-49.

24. Kassaw, A. (2007).Major Animal Health problems of market oriented livestock Development in FogeraWoreda. DVM Thesis, FVM, Addis Ababa University DebreZeit, Ethiopia.

25. Kahn, C.M. (2011). The Merck veterinary manual. 10th ed. White-house Station, NJ: Merck. \& Co., Inc; 273-1036.

26. Marqurdt, C.R., \& Greive, B.R. (2000). Parasitology and vector biology.2nd ed. Sandiago. Harcourt academic press, 265-272.

27. CDC.(2012). Parasite and health. Schistosomiasis.h ttp//www.dpd.cdc.gov/dpdx/HTML/ Schistosomiasis.htm.

28. Hailu, B., Shibru, T., Leykun, J. (1998). Schistosomiasis in Ethiopia and Eritrea. Institute of pathobiology, Addis Ababa University, $3^{\text {rd }}$ edition

29. Solomon, O. (2008). Observations on the prevalence of schistosoma bovis infectionin Bahir Dar area, North Central Ethiopia. DVM Thesis: Faculty of Veterinary medicine, Mekele University, Ethiopia.

30. Amine, G., Krok, B., \& T. Bogale. (2001). Preliminary study on the major bovine trematode infection around Kemissie, Northeastern Ethiopia and treatment trial with Praziquantel. Bulletin of Animal Health and Production in Africa, 49: 62-67.

31. Haile, S., Golassa, L. Mekonnen, Z. (2012). Prevalence of Schistosomamansoniandeffectiveness of Praziquant 
el in school children in Fincha valley, Ethiopia. Jou rnal of Parasitology and Vector Biology, 4: 25-30.

32. Baugh, S.C. (1978). Cited by Southgate, V.R and Agrawal, M.C. Schistosomiasis in India. Parasitol. Today, 6: 166-168.

33. Bont, J.D. (1995). Cattle schistosomiasis. Host para site interaction. PhD thesis, Universities, Gent, 2327.

34. Haile, S. (1987). Schistosomiasis in domestic rumi nants in Bahir Dar. Proceedings of the first Nationa 1 livestock improvement conference, Addis Ababa, Ethiopia, 122-124

35. Bedarkar, S.N., Narladkar, B.W., \& Deshpande, P.D. (2000). Seasonal prevalence of snail fluke infections in ruminants of Marathwada region. Journal of Veterinary Parasitology, 14(1): 51-54.

36. Magona, J.W., \& Musisi, G. (2002). Influence of age, grazing system, season and agro climatic zone on the prevalence and intensity of gastrointestinal strongylosis in Ugandan goats. Small Ruminants Research, 44: 187-192.

37. Houdijk, J.G.M., \& Athana, S.S.A. (2003). Direct and indirect effects of host nutrition on ruminants gastrointestinal parasites. In: Proceedings of the sixth International symposium on the nutrition of herbivores. Merida Mexico.

38. Alemseged, G. (2010). Prevalence of bovine schistosomiasis in Dembia District North west Ethiopia. Dvm thesis, faculty of veterinary medicine. Gondar, Ethiopia.

39. Majid, A., A, Marchall, T.F., \& Hussein, M., F, (1980). Observations on cattle schistose miasis in the Sudan, a study on comparative medicine. I. Epizootical observations on Schistosoma bovisin the White Nile Province. Am J Trop Med Hyg, 29: 435-441.8.

40. Bushara, H., O, Omer, O., H, Malik. K., H., E and Taylor, M., G. (1994). The effect of multiple transfers of immune serum on maturing Schistosoma bovis infections in calves. Parasitol Res; 80: 198-202.

41. De Bont, J, Vercruysse J. (1997). The epidemiology and control of cattle schistosomiasis. Parasitol, 13:255-262.

42. Mersha, C., Belay,D., \& Tewodros, F. (2012). Prevalence of Cattle schistosomiasis and Associated Risk Factors in Fogera Cattle, South Gondar Zone and Amhara National Regional State, Ethiopia. Journal of Advanced Veterinary Research, 2: 53-56.

43. Belayneh, L., \& Tadesse, G., (2012). Bovine schistosomiasis: A Threat in Public Health perspective in Bahir Dar Town, Northwest Ethiopia. Acta Parasitological Globalis, 5(1): 1-6.

44. Chitsulo, L, Engels, D, Montresor, A., \& Savioli, L. (2000). The global status of schistosomiasis andits control. Acta Trop., 77: 41-51.

45. World Health Organization (WHO). (2004). WHO: Prevention and Control of
Schistosomiasis and SoilTransmitted Helminthiasis . WHO Technical Report Series, Geneva.

46. World Health Organization (WHO). (2007). Schistomiasis. WHO Fact Sheet No 115. Geneva.

47. Dale, V., H., \& Polasky, S. (2007). Measures of the effects of agricultural practices on ecosystem services. Ecol. Econ. 64:286-296.

48. Boelee, E., \& Madsen, H. (2006). Irrigation and sc histosomiasis in Africa: Ecological as pects. Colom bo, Sri Lanka: International Water Management Institute. IWMI Research Report 99:39.

49. Fraser, C.M., Bergeron, J.A., Maya, A., \& Susan, E.A. (1991). The Merck veterinary manual: A handbookof diagnosis, therapy, and disease prevention and control for the veterinarian, $7^{\text {th }}$ edition U.S.A, Merck and Co., Inc, 76-78.

50. Brown, D., S. (1980). Fresh water snails of Africa and their medical important. London: Taylor and fransisp. 482.

51. Jones, T.C., Hunt, R.D., King, N.W. (1997). Veterinary pathology, 6ed. Lippincott Williams and Wilkins, Maryland, 664-667.

52. Donald P. McManus, ${ }^{1}$ Darren J. Gray, ${ }^{1,2,3}$ Yuesheng Li, ${ }^{1}$, Zheng Feng, ${ }^{5}$ Gail M. Williams, ${ }^{2}$ Donald Stew art, ${ }^{3}$ Jose Rey Ladino, ${ }^{3}$ and Allen G. Ross ${ }^{3}$.(2010). S chistosomiasis in the People's Republic of China: the Era of the Three Gorges Dam.

53. Olds, G., R., \& Mahamoud, A., A. (1980). Role of host granulomatous response in murine schistosoma mansoni. Eosinophilsmediated distraction of eggs. The American Society for clinical investigation, 66: 1191-1199.

54. Kogulan, P., \& Lucey, R., D. (2005). Schistosomosis medicine specialties, 6: 1-11.

55. Hailu, M. (1999). Observations on the prevalence and intensity of Schistosoma bovis infection in Bahir Dar area, north central Ethiopia. DVM Thesis, Faculty of Veterinary Medicine, Addis Ababa University.

56. Zangana, I., \& Aziz,

K. (2012). Prevalence and pathological study of Schistosomiasis. In sheep in Akra (Dohuk province, North Iraq. Iraq Journal of veterinary Science, 26:125-130.

57. Urquhart, G., M, Armour, J., Duncan, J., L., \& Jennings, F., W. (1997). Veterinary helminthology: Veterinary Parasitology. New York: Churchill Livingstone Inc, 114-116.

58. Hendrix, M.C., \& Robinson, D, E., (2006). Diagnostic Parasitology for Veterinary Technicians, 3rd ed. New York: Academic press.

59. Urquhart, G., M, Armour, J, Duncan, J., L, Jennings, F., W. (1987). Veterinary helminthology: Veterinary Parasitology. New York: Churchill Livingstone Inc,114-116.

60. Imadeldin, E. A. Elabbas, M. A. Sanaa, A. H. Hans, P. R. (1995). A review on the diagnosis infection in cattle of schistosoma bovis: current status and future prospectsCienc. Rural, 25(3). 
61. Jiafu, Y.E., Zhang, C., Yafank, L. (1984). Circumoval precipitin test in patient in region of Schistosoma Japonicum for which snails have ar have not been eradicated. Journal of Parasitology and Parasitic diseases, 2, 160.

62. Ouchterloney, O. (1958). Diffusion in gel: method for immunological analysis. Progress in Allergy. 5, 1-78.

63. Aradaib, I.E, Abbas, B., Bushara, H.O. (1993). Evaluation of Schistosoma bovis adultworm extract for vaccination of calves. Preventive Veterinary Medicine, 16, 77- 84.

64. Haroun, E.M. (1973). Observations on the serodiagnosis of animal and human schistosomiasis in the Sudan. In: veterinary conference.

65. Murare, H.M. (1983). Studies on the host parasite relationship of Schistosoma bovis in the mouse. $\mathrm{PhD}$. Thesis, University of London, 383.

66. Aradaib, I.E., Abbas, B., Bushara, H.O. (1994b). ELISA for Schistosoma bovis vaccine: preliminary report. Ciência Rural, 24(3), 563-566.

67. Aradaib, I.E. (1992). Evaluation of Schistosoma bovis adult worm extracts for vaccination of calves. Thesis (Master of Preventive Veterinary Medicine) - University of California, Davis, USA.

68. Hussien, M.F. (1972). Preliminary observation on the use of indirect fluorescent antibody techniques in the diagnoses of bovine schistosomiasis. Sudan Journal of Veterinary Science and Animal Husbandry, 13, 21-26.

69. Schiniki, D. V., Clutter, W.C., Murrel K.D. (19760). Enzyme and I125-labeled antiimmunoglobulin assay in the immunodiagnosis of schistosomiasis. American Journal of Tropical Medicine and Hygiene, 25, 824-831.

70. Voller, A., Bartlett, A., \& Bidwell, D.E. (1976). Enzyme immunoassay for Parasitic diseases. Transaction of the Royal Society of the Tropical Medicine and Hygiene, 70, 98-106.

71. Huldt, G., Lagerquist, B., Philips, T.C.C. (1975). Detection of antibodies in schistosomiasis by enzyme-linked immunosorbent assay and immunoprecipitation methods. Anuals of Tropical Medicine and Parasitology, 69, 483-488.

72. Aradaib, I.E. (1988). Serologic studies on bovine schistosomiasis. Thesis (Master in Veterinary Medicine), University of Khartoum, Sudan.
73. Aradaib, I.E., Omer, O.H., Abbas, B. (1994a). Schistosoma bovis whole-egg antigen,Did not protect zebu calves against experim ental schistosomiasis. Preventive Veterinary Medicine.

74. Matsuda, J., Tanaka, H., Blas, B.L. (1984). Evaluation of ELISA with ABTS, 2, 2- azino-di-(3ethyl benothiazoline sulfonic acid), as the substrate of peroxidase and its application to the diagnosis of schistosomiasis. Japanese $\mathbf{J}$ of Experimental Medicine, 54,. 131-139.

75. Bushara, H.O., Bashir, M.E.N., Malik, K.H.E. (1993). Suppression of Schistosoma bovis egg production in caule by vaccination with glutathione S-transferase or Keyhole limpet haemocyanin. Parasite Immunology, 15, 383-390.

76. Balloul, J.M., Sondermeyer, P., Dreyer, D. (1987). Molecular cloning of a protective antigen of schistosomes. Nature, 326, 149-153.

77. Trrottein, F., Godin, C., Pierce, R.J. (1992). Inerspecies variation of schistosome $28-\mathrm{KD}$ glutathione S-transferase. Molecular and Biomedical Parasitology, 54, 63-72.

78. McCauley, E.H., Majid, A.A., \& A. Tayed. (1984). Economic evaluation of the production impact of bovine schistosomiasis and va ccination in the Sudan. Preventive Veterinary Medicine, 2: 735-754.

79. WHO. (1999). Report of the WHO informal consultation of schistosomiasis control.WHO/CDS/SIP/99.2, WHO, Geneva.

80. Touré, S., Zhang, Y., Bosqué-Oliva, E., Ky, C., Ouedraogo, A., Koukounari, A., Gabrielli, A.F., Sellin, B., Webster, J. P., Fenwick, A. (2008). Two year impact of single praziquantel treatment on infection in the national control program on schistosomiasis in Burkina Faso. Bulletin of the World Health Organization.86, 780-787

81. WHO.(2012). Schistosomiasis. http://www.who.int/ mediacentre/factsheets/fs115/en/in dex.html.

82. Hotez, P.J., Molyneux, D.H., Fenwick, A.(2007). C ontrol of neglected tropical diseases.The New Engl and Journal of Medicine, 357: 10181027. Doi10.1056/NEJMra064142.

83. Donald, G. McNeil, Jr. (2005). Schistosomiasis (Bilharzia) control and prevention. The Carter Center schistosomiasis control program. 